\title{
A critique of post-occupancy evaluation in the UK
}

\author{
Isaiah Oluremi Durosaiye ${ }^{1}$ (D) Karim Hadjri $^{1} \cdot$ Champika Lasanthi Liyanage $^{2}$
}

Received: 18 January 2018 / Accepted: 18 January 2019 / Published online: 7 February 2019

(c) The Author(s) 2019

\begin{abstract}
Architects are trained to design buildings and the subjective perception of building users may not be easy to translate into a designer's language. In the UK, the design profession has not fully appreciated the significance of returning to the erected structure to appraise how well it was, and remained, fit for purpose. This paper presents a critique of the state of the art of post-occupancy evaluation (POE) in the UK building procurement process. It is established that despite the known benefits of POE, the culture of evaluating the performance of a building, after it has been built and occupied by users for a while, has not been successfully embedded in the design and procurement process. The authors advocate for a 'forward feeding' POE, which embraces early collaboration between end users and designers in the building procurement process, in order to co-create a liveable built environment.
\end{abstract}

Keywords Architect $\cdot$ Building performance evaluation $\cdot$ Building procurement $\cdot$ Postoccupancy evaluation $\cdot \mathrm{UK}$

\section{Background}

This is a critique of the state of the art of post-occupancy evaluation (POE) of buildings in the UK. POE was first introduced in the United States to appraise the performance of buildings after they have been handed over and while occupied. POE has been fundamentally described as "... any and all activities that originate out of an interest in learning how a building performs once it is built, including whether and how well it has met expectations and how satisfied building users are with the environment that has been created" (Vischer 2002, p. 23). According to Preiser (1995, p. 19), POE is a process of “...systematically comparing actual building performance, with explicitly stated performance criteria." Traditionally, POE has been used to establish user satisfaction; alongside the building meeting other preset technical criteria. Clements-Croome (2014, p. 92) defines POE “... as the examination of the effectiveness of the design environment for human users." In a later study, Preiser (2001) proposed that the evaluation of building performance may be undertaken quantitatively or qualitatively. He acknowledged that most of the performance

Isaiah Oluremi Durosaiye

i.durosaiye@sheffield.ac.uk

1 School of Architecture, University of Sheffield, Arts Tower, Western Bank, Sheffield S10 2TN, UK

2 University of Central Lancashire, Preston, UK 
indicators of a building are quantifiable, such as lighting, temperature, acoustics and humidity. However, Preiser (2001) contends that while a building may show a set of excellent indicators in the quantifiable domain, its occupants may still not be entirely comfortable and satisfied using it. POE has therefore developed to be a methodological approach that can be used to examine the performance of a building by focusing on user satisfaction and identifying "... ways to improve building design, performance and fitness for purpose, through the systematic evaluation of the buildings in use, from the perspective of the people who use them" (Turpin-Brooks and Viccars, 2006, p. 178).

Apart from the overarching goal of delivering user satisfaction, there is an array of reasons for which POEs are commissioned, and quite a few approaches or methodologies by which they may be accomplished. Preiser (2001) identified three different types of POEs, namely indicative, investigative and diagnostic:

1. An indicative POE is said to give an indication of the strengths and weaknesses of the building. This kind of POE is conducted by interviewing users most conversant with the building (or space), combined with a walkthrough observation of the facility. The intended outcome of an indicative POE is to create an awareness of issues in building performance.

2. An investigative POE is undertaken to ascertain how a building type complies with pre-set criteria or performance standards. The expected outcome of this type of POE is to determine the causes and effects of issues in building performance.

3. A diagnostic POE attempts to establish the relationship between the objective measures of the physical environment and the subjective occupant perception of the building performance.

Furthermore, while POE may be used to determine the compliance of a building with pre-set standards by measuring its technical attributes (Nicol and Roaf 2005), it must be emphasised that a POE is not a mere measure of the objective performance of the building in areas such as spatial adequacy, lighting, heat insulation, acoustics and ventilation. POEs have been found useful in exploring cause-effect relationships between these technical features and the subtle users' experiences and needs (Kim et al. 2013). Hence, a POE may be used to determine users' actual spatial usage or occupants' subjective thermal comfort, which may not necessarily correlate with the technical performance of the building. As an example, Becker (2018) pointed at the failure of the design profession's ability to fully identify and embrace users' needs and expectation, suggesting that the marrying of the design professionals' expertise with the social scientists' knowledge of environmental behavioural may help resolve this conundrum, and bridge the gap between user expectation and contemporary architectural design ethos. A POE exercise should be driven by the need "...to capture and disseminate lessons in order to support better decision-making in the briefing, budgeting, design, construction and operation..." stages of a building (Bordass 2003, p. 407).

\section{Issues with POE in the UK}

Architects are trained to design buildings and the subjective perception of building users may not be easy to translate into a designer's language. However, the design profession has not fully appreciated the significance of returning to the erected structure in order to 
appraise how well it was, and remained, fit for purpose. In the UK in particular, despite the known benefits of POE, the culture of evaluating the performance of a building after it has been built has not been successfully embedded in the design and procurement process in the last five decades since its introduction in the US in the 1960s (Cooper 2001). Hadjri and Crozier (2009, p. 21) acknowledged this suboptimal culture of POE in the UK and, in comparison to the USA, Canada and Australia, argue that the latter group of countries "...have a more mature POE culture than the UK". There seem to be a sense of hesitation among building professionals to embrace the application of POE in practice. This is even more surprising because as early as 1965 the Royal Institute of British Architects (RIBA) in its Handbook of Architectural Practice and Management, recommended the implementation of Stage M: "Feedback", as the final part of its Plan of Work, which required that architects revisit their design work after it has been constructed and occupied for 2-3 years in order to glean from it knowledge that may be used for the services of future clients (Bordass and Leaman 2005). After more than a decade, the lukewarm reception Stage $M$ received from the industry prompted RIBA to withdraw this feedback 'stage' from the Architect's Appointment in 1972 (Bordass and Leaman 2005). More recently, RIBA introduced the explicit use of POE in the revised version of its handbook, under Plan of Work, Stage 7, (Clements-Croome 2014), as a tool to improve the quality of buildings and meet end users' need and expectations. However, business and market pressures do not simply permit designers and builders to be interested in a building's performance after handover, as they move on to the next project (Way and Bordass 2005). Consequently, after more than half a century since its first introduction by RIBA, POE is still a scanty endeavour of research-oriented academics, rather than being an embedded practice in the building procurement process in the UK.

One of the reasons for this indifference on the supply side of the building procurement industry is that there are hardly any incentives for design professionals to be interested in the performance of a building after it has been commissioned. Cooper (2001) suggests that the slowness of the UK building profession to adopt the use of POE as a standard part of the building procurement process lies in the way architects are rewarded. A further obstacle to the mainstreaming of POE may be due to it being perceived as a potential source of conflict among stakeholders (Meir et al. 2009), as designers may simply not have a vested interest in exposing design errors which may result in potential liability and/or litigation (Riley et al. 2010). Another major impediment to the widespread use of POE is its retrospective nature (Way and Bordass 2005). Building users and occupants may fail to buy into the POE scheme as part of the procurement project, as they may not see that the potential benefits derived from the process are commensurate with the disruption any retrofitting work would cause them, and they may not be able to use the insight gained through the POE exercise in the foreseeable future (Preiser 2003). As its name implies, 'post' occupancy evaluation is seen by some interested stakeholders as an afterthought, and that even if valuable information is garnered from the process, the present occupants may not readily benefit from such an exercise. The optimal outcome of a POE exercise for the present occupant is thus to 'retrofit'; i.e. correct already committed mistakes, and not preventing them from occurring in the first instance. Furthermore, there are no agreed indicators that may be used for the evaluation of the performance of a building (Zimmerman and Martin 2001) from the occupants' perspectives; and owners and users of buildings may not have the technical expertise to appreciate the benefits that may result from a well-commissioned POE (Vischer 2002). Likewise, there are currently no incentives for designers, developers, owners and occupants of building to take ownership of the POE, as an inherent part of the building procurement process. All these factors might have contributed to the lacklustre 
engagement of the UK building procurement industry in POE. Hence, there is a dearth of literary evidence of designers' perspectives on the conduct of POE.

Over the decades after POE was first introduced in the United States, a number of alternative terms to POE have been circulated in the architectural design and research literature in the UK, the most prominent of which is 'building performance evaluation' (Manning 1965), which was later conceptualised, formalised and structured by Wolfgang Preiser, one of the pioneers of POE (Preiser and Schramm 2002). However, its initial momentum soon disintegrated into ad hoc market practices (Kelly et al. 2012). Concerns have been raised about the lukewarm approach of the construction industry stakeholders to embrace POE and incorporate it in mainstream building procurement procedures in the UK (Stevenson and Leaman 2010). In their study, Stevenson and Leaman (2010) point at the possibility to change building occupants' behaviour by feeding back on how efficient they are in their energy usage practices. While such information feedback may help influence occupants' behaviour in a positive direction, it is only an indirect measure of building performance. Therefore, unless an objective evaluation of a building's energy efficiency is undertaken, stakeholders would not obtain the full picture of the interplay between the building and its occupants. Stevenson and Leaman (2010) were quick to point out that any cause-effect relationships deducted in such evaluation scheme would be misrepresented and, therefore, inconclusive. Nevertheless, the occupants' behavioural elements of a building performance evaluation should not be disregarded or underestimated in the POE process.

Apart from its conundrums with POE, the UK construction industry had in the past been highly criticised for its lack of attention to client needs. For example, in The Report of the Construction Taskforce, Sir John Egan noted that one of the most crucial problems the building industry was facing was end user dissatisfaction with the built form (Egan 1998). The taskforce, which was commissioned to undertake a diagnostic status investigation of the UK construction industry, found that the outcomes of projects were unpredictable with respect to time, cost and quality. Despite the challenges of mainstreaming POE into the building procurement process in the UK, the construction industry has made substantial shift towards improving efficiency in the construction phase over the last two decades, which has resulted in more timely delivery of projects and buildings of higher standards. These are the results of not just political drive, but also legislative instruments. More stringent building regulatory standards and an increasing appreciation of user expectations, especially in the special purpose and public buildings like healthcare estates, educational facilities and office buildings have given impetus to engaging users in building evaluation practices in the UK (Menezes et al. 2012). Public buildings are now expected to exhibit features that meet the needs of a wide range of users on the continuum of age (i.e. young and old); wellbeing (healthy and ill); abilities (disabled and able-bodied); and diverse sociocultural background. Some of these requirements were considered niche design features a few decades ago.

One of the legislative driving forces for mainstreaming POE in the UK building procurement industry is the European agenda on sustainability and sustainable buildings. The Energy Performance in Buildings Directive (Directive 2002/91/EC), established minimum energy requirements for new buildings and large existing buildings that are subject to major renovations (European Union 2002). In a recast of this directive (Directive 2010/31/ EU) in 2010, the European Union required Member States to draft national action plans to increase the number of nearly zero-energy buildings; i.e. buildings that consume very low energy or use energy predominantly from renewable sources, including sources near to the site of consumption (European Union 2010). One of the cornerstones of the UK National Energy Efficiency Action Plan is the energy efficiency in building policy, with particular 
focus on energy efficient building renovations (Department of Energy and Climate Change 2014). Energy performance, acoustics, fire safety and accessibility requirements are some of the many standards modern buildings must meet. Complying with all these regulatory requirements and standards in turn demands articulation of the various perspectives of a multidisciplinary team of experts, which can be facilitated by a POE regime (Preiser 1995).

While POE focuses on end-users' perception of a building's performance, the development of building performance evaluation has been mostly driven by the sustainability agenda over the last two decades (Cole 1998). In a number of countries, building performance certification systems for benchmarking, akin to POE, have evolved. For example, the Leadership in Energy and Environmental and Design (LEED), championed in the United States, is a gauge of the carbon footprint of a building, based on its environmental impact assessment (LEED 2018). The German Sustainable Building Council is a certification system that evaluates a building's impact on people, environment, and commercial viability, using the life cycle assessment methods (DGNB 2018). The UK's Building Research Establishment Environmental Assessment Method (BREEAM), on the other hand, takes a holistic approach to assessing environmental, social and economic sustainability performance of a building (BRE 2018).

The broader spectrum of 'stakeholders' interests has also necessitated the evolution of other forms of building performance evaluation (Johansson 2012). For instance, a building performance evaluation process such as commissioning is often conducted to assess the energy efficiency of buildings; a process that may also illuminate a range of operational problems including acoustics, indoor air quality, landscaping, safety, security, waste disposal and water use (Mills 2011). The American Society of Heating, Refrigerating and Air Conditioning Engineers (ASHRAE), has a long-established certification system for thermal comfort and indoor air quality based on the subjective perception user satisfaction (ASHRAE 2018).

\section{The Way forward}

Way and Bordass (2005) argue for a 'forward feeding' POE, which may help in aligning expectations of designers and users. It has been established that once clients and users of existing buildings appreciate the business case for managing their facilities through POEs, future design briefs can be informed in order to build better performing buildings (Fisk 2001). Way and Bordass contend that a POE should feed forward for clients and feedback for designers. Central to such an argument is that POE may no longer be fit for purpose as a means of testing users' satisfaction with the built environment, due to its retrospective nature. Way (2006) later introduced an alternative approach to obtaining feedback about the performance of buildings. 'Soft Landings' was piloted on a corporate headquarters migration project, in which Mark Way (2006) was the lead architect. The Soft Landings initiative affects three critical stages of the building procurement project; namely: (1) briefing/programming; (2) handover and (3) aftercare. One of the critical success factors of Soft Landings was that the lead architect was actively involved in the handover stage and remained resident 'in situ' post-handover, offering aftercare services to the client, by monitoring on site the actual performance of the building for the first 3 years after handover. Way and Bordass (2005) argue that the aftercare involvement of the designer in Soft Landings was not just an optional 'add-on' to the project, but was an integral part of the contractual obligations of the project team. These obligations were detailed in a licensed Scope 
of Service document set. The underlying objective of the Soft Landings initiative was to “...increase designer and constructor involvement during and after handover of buildings to help clients get the best out of their new building..." and, thereby, reduce tensions that often arise during the initial period of occupancy (Way 2006, p. 25.). According to Mark Way, while Soft Landings delivers the greatest benefit for users in the aftercare stage, the collaboration between the design/constructor team and the client/user team actually starts at the briefing/programming stage, when the design brief is being constructed. As a minimum, the Scope of Service document would spell out the following terms of cooperation between the designer/constructor team and the user/occupant team:

(a) greater clarity of the duties of all parties during key stages;

(b) increased designer and constructor involvement before and after occupation;

(c) a resident Soft Landings team during the users' initial settling-in period; and

(d) monitoring and review of building performance for 3 years (Way and Bordass 2005).

Mark Way concluded that apart from the obvious benefits for occupants/users, Soft Landings add measurable values to the business activities of the suppliers of building projects. The early stage collaboration reduces 'rework' and associated costs for the design team, creates an effective building readiness and better fine-tuning to improve the end product and the experience of clients and users, which increases the chances of the designer being referred in the future. A further advantage is that the wealth of knowledge accumulated over the 3 years of active follow up by the design team provides a good database for future POE and benchmarking of the project against itself and other projects. The extra cost associated with Soft Landings was “...less than $0.25 \%$ of the construction cost on a full-scope appointment" (Way and Bordass 2005, p. 354). Despite these acclaimed benefits of Soft Landings and after more than a decade since it was first introduced, there are hardly any literary accounts of a follow up to the initiative. It has neither become a mainstream industry practice nor a niche approach to evaluating the performance of buildings. However, there may be some limitations to making initiatives such as Soft Landings a routine. For instance, not all projects are big enough to pay the extra cost of continuous engagement of the lead architect for 3 years after handover. Furthermore, there may simply not be sufficient space on site to accommodate a project team in house for the length of time required by the architect to reside in situ and observe the performance of a building. To overcome some of these practical challenges, occupants' perspectives on building performance may now be sought through online surveys (Amasyali and El-Gohary 2016), while the building information modelling system is an integrative design process that enables the subsequent retrieval of certain performance indicators, with minimal disruption to the daily function of occupants (Eastman et al. 2011). The starting point for the Soft Landings initiative is the briefing/programming stage, which is often supported by the building information modelling system.

\section{Concluding remarks}

Despite increasing interest in the academic and research realms in the post-occupancy evaluation of buildings in the UK, the people involved in building procurement process seldom engage closely with the performance of the buildings they have created. However, if well implemented, a POE may be used to make important strategic decisions during the 
operating lifespan of the building. Local authorities, or other non-governmental interest groups should consider the creation of a publicly available POE databases where designers', builders' and occupants' experiences about a building's performance could be deposited. As more items are stored and as it grows over time, facilities managers may use information from such a POE depository to make strategic decisions in a proactive manner, rather than using the information derived from a POE to undertake retrofitting and renovations (Eley 2001).

Acknowledgements The authors wish to acknowledge the financial support provided by University of Central Lancashire, UK, through the PhD bursary awarded in 2013, to the corresponding author, Isaiah Oluremi Durosaiye.

\section{Compliance with ethical standards}

Conflict of interest The authors declare that they have no conflict of interest.

Open Access This article is distributed under the terms of the Creative Commons Attribution 4.0 International License (http://creativecommons.org/licenses/by/4.0/), which permits unrestricted use, distribution, and reproduction in any medium, provided you give appropriate credit to the original author(s) and the source, provide a link to the Creative Commons license, and indicate if changes were made.

\section{References}

Amasyali, K., \& El-Gohary, N. M. (2016). Energy-related values and satisfaction levels of residential and office building occupants. Building and Environment, 95, 251-263.

ASHRAE. (2018). American Society of Heating, Refrigerating and Air Conditioning Engineers [Online]. United States: American Society of Heating, Refrigerating and Air Conditioning Engineers. Available: https://www.ashrae.org/about. Accessed 24 Dec 2018.

Becker, F. (2018). Post-occupancy evaluation: Research paradigm or diagnostic tool. In W. F. E. Preiser, A. E. Hardy, \& U. Schramm (Eds.), Building performance evaluation. Berlin: Springer.

Bordass, B. (2003). Learning more from our buildings-Or just forgetting less? Building Research \& Information, 31, 406.

Bordass, B., \& Leaman, A. (2005). Making feedback and post-occupancy evaluation routine 3: Case studies of the use of techniques in the feedback portfolio. Building Research \& Information, 33, 361-375.

BRE. (2018). Building Research Establishment Environmental Assessment Method [Online]. United Kingdom: Building Research Establishment. Available: https://www.breeam.com/. 24 Dec 2018.

Clements-Croome, D. (Ed.). (2014). Post-occupancy evaluation. In Intelligent buildings: An introduction. UK: Routledge.

Cole, R. J. (1998). Emerging trends in building environmental assessment methods. Building Research \& Information, 26, 3-16.

Cooper, I. (2001). Post-occupancy evaluation-Where are you? Building Research \& Information, 29, $158-163$.

Department of Energy and Climate Change. (2014). In Change DOEC (Ed.). The UK's National Energy Efficiency Action Plan and Building Renovation Strategy. Department of Energy and Climate Change, London, UK.

DGNB. (2018). German Sustainable Building Council (DGNB) [Online]. Germany German Sustainable Building Council (DGNB). Available: https://www.dgnb.de/en/council/dgnb/. Accessed 24 Dec 2018.

Eastman, C., Teicholz, P., Sacks, R., \& Liston, K. (2011). BIM handbook: A guide to building information modeling for owners, managers, designers, engineers and contractors. Hoboken: Wiley.

Egan, J. (1998). Rethinking construction-The report of the construction taskforce [Online]. United Kingdom: Building Research Establishment. http://constructingexcellence.org.uk/resources/rethinking -construction-the-egan-report/. Accessed 24 Dec 2018.

Eley, J. (2001). How do post-occupancy evaluation and the facilities manager meet? Building Research \& Information, 29, 164-167. 
European Union. (2002). Energy performance of buildings directive [Online]. European Commission. Available: http://www.epbd-ca.eu/. Accessed 17 Jan 2018.

European Union. (2010). Energy performance of buildings directive (Directive 2010/31/EU) [Online]. European Commission. Available: http://www.epbd-ca.eu/. Accessed 27 Dec 2015.

Fisk, D. (2001). Sustainable development and post-occupancy evaluation. Building Research \& Information, 29, 466-468.

Hadjri, K., \& Crozier, C. (2009). Post-occupancy evaluation: Purpose, benefits and barriers. Facilities, 27, 21-33.

Johansson, O. (2012). The spatial diffusion of green building technologies: The case of Leadership in Energy and Environmental Design (LEED) in the United States. International Journal of Technology Management \& Sustainable Development, 10, 251-266.

Kelly, S., Crawford-Brown, D., \& Pollitt, M. G. (2012). Building performance evaluation and certification in the UK: Is SAP fit for purpose? Renewable and Sustainable Energy Reviews, 16, 6861-6878.

Kim, M. J., Oh, M. W., \& Kim, J. T. (2013). A method for evaluating the performance of green buildings with a focus on user experience. Energy and Buildings, 66, 203-210.

LEED. (2018). Leadership in Energy and Environmental Design [Online]. United States: Leadership in Energy and Environmental Design. Available: https://new.usgbc.org/leed. Accessed 24 Dec 2018.

Manning, P. (1965). Office design: A study of environment [Online]. United Kingdom: Educational Resources Information Center. https://eric.ed.gov/?id=ED033529. Accessed 24 Dec 2018.

Meir, I. A., Garb, Y., Dixin, J., \& Cicelsky, A. (2009). Post-occupancy evaluation: An inevitable step toward sustainability. Advances in Building Energy Research, 3, 189-219.

Menezes, A. C., Cripps, A., Bouchlaghem, D., \& Buswell, R. (2012). Predicted vs. actual energy performance of non-domestic buildings: Using post-occupancy evaluation data to reduce the performance gap. Applied Energy, 97, 355-364.

Mills, E. (2011). Building commissioning: A golden opportunity for reducing energy costs and greenhouse gas emissions in the United States. Energy Efficiency, 4, 145-173.

Nicol, F., \& Roaf, S. (2005). Post-occupancy evaluation and field studies of thermal comfort. Building Research \& Information, 33, 338-346.

Preiser, W. F. (1995). Post-occupancy evaluation: How to make buildings work better. Facilities, 13, 19-28.

Preiser, W. F. E. (2001). The evolution of post-occupancy evaluation: Toward building performance and universal design evaluation. In Stanley, L. (Ed.), Learning from our buildings: A state-of-the-practicesummary of post-occupancy evaluation. US: National Academy Press.

Preiser, W. F. E. (2003). Continuous quality improvement through post-occupancy evaluation feedback. Journal of Corporate Real Estate, 5, 42-56.

Preiser, W. F. E., \& Schramm, U. (2002). Intelligent office building performance evaluation. Facilities, 20, 279-287.

Riley, M., Kokkarinen, N., \& Pitt, M. (2010). Assessing post occupancy evaluation in higher education facilities. Journal of Facilities Management, 8, 202-213.

Stevenson, F., \& Leaman, A. (2010). Evaluating housing performance in relation to human behaviour: New challenges. Building Research \& Information, 38, 437-441.

Turpin-Brooks, S., \& Viccars, G. (2006). The development of robust methods of post occupancy evaluation. Facilities, 24, 177-196.

Vischer, J. (2002). Post-occupancy evaluation: A multifaceted tool for building improvement. In L. Stanley (Ed.), Learning from out buildings: a state-of-the-pracfice summary of post-occupancy evaluafion. US: National Academy Press.

Way, M. (2006). Soft Landings: A fresh scope of service that ensures users and clients get the best out of a new building. Journal of Facilities Management, 4, 23-39.

Way, M., \& Bordass, B. (2005). Making feedback and post-occupancy evaluation routine 2: Soft landings involving design and building teams in improving performance. Building Research \& Information, 33, 353-360.

Zimmerman, A., \& Martin, M. (2001). Post-occupancy evaluation: Benefits and barriers. Building Research \& Information, 29, 168-174.

Publisher's Note Springer Nature remains neutral with regard to jurisdictional claims in published maps and institutional affiliations. 